\title{
TOURISM AND REGIONAL INCOME INEQUALITY: EVIDENCE FROM CHINA*
}

\author{
Hengyun $\mathrm{Li}^{a}$, Jason Li Chen ${ }^{b}$, Gang $\mathrm{Li}^{*}$ and Carey $\mathrm{Goh}^{c}$
}

Affiliations:

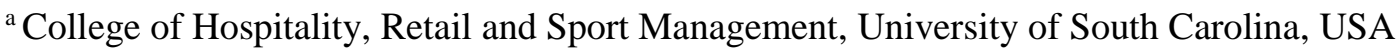

${ }^{\mathrm{b}}$ School of Hospitality and Tourism Management, University of Surrey, UK

${ }^{c}$ School of Hotel and Tourism Management, The Hong Kong Polytechnic University, Hung Hom, Kowloon, Hong Kong SAR, China

Contacts:

a Tel: +1 (803) 220 5172; Fax: +1 (803) 777 6427; Email: hengyun@email.sc.edu

b Tel: (44) 1483 686664; Fax: (44) 1483 689511; Email: 1.chen@ surrey.ac.uk;

cTel: (852) 3400-2156; Fax: (852) 2362-9362; Email: carey.goh@ polyu.edu.hk

\begin{abstract}
This study examines the role of tourism development in reducing regional income inequality in China. First, the theoretical foundation for how tourism affects regional income inequality is discussed. Second, based on the conditional convergence framework, this study proposes a spatiotemporal autoregressive model to capture spatial and temporal dependence as well as spatial heterogeneity. Tourism development is introduced as a conditional convergence factor in an attempt to examine whether the convergence speed is accelerated by regional tourism development. Third, the effects of international and domestic tourism in narrowing regional inequality are compared both globally and locally. The empirical results indicate that tourism development contributes significantly to the reduction of regional inequality, with domestic tourism making a greater contribution than international tourism.
\end{abstract}

Key Words: tourism development, regional inequality, domestic tourism, international tourism, spatial analysis, local spatiotemporal autoregressive model

\footnotetext{
- Please cite this article as: Li, H., et al. Tourism and regional income inequality: Evidence from China. Annals of Tourism Research (2016), http://dx.doi.org/10.1016/j.annals.2016.02.001

* Corresponding author at: School of Hospitality and Tourism Management, University of Surrey, Guildford, Surrey, GU2 7XH, UK. E-mail address: g.li@surrey.ac.uk; Tel: (44) 1483 686356; Fax: (44) 1483689511.
} 


\section{INTRODUCTION}

Travel and tourism continues to be one of the world's largest industries and fastest growing sectors (WTTC, 2011). Sinclair (1998) highlights the important role that the tourism sector plays in creating jobs and generating revenue for a destination's residents and government. Furthermore, the tourism benefits that spill over to influence many other economic activities strengthen the positive effects of tourism on economic growth (Proenca \& Soukiazis, 2008). As such, tourism development is widely recognized as a positive instrument for promoting economic growth (Chou, 2013). Overall, the literature focuses almost exclusively on traditional metrics of growth such as income and employment (Deller, 2010), and distributional issues such as poverty rates or changes in regional inequality have been neglected.

According to Williams and Shaw (1991), tourism distributes development from economic centers to less developed areas. Thus, tourism development tends to be used as an instrument to narrow regional gaps. In fact, the tourism industry in China (The $12^{\text {th }}$ Five-year Tourism Development Plan, 2010) and the European Union (Wanhill, 1997) serves as a growth pole for less developed and rural areas to promote economic growth. However, some scholars question the quality of growth generated by tourism and recreation (Parrilla, Font, \& Nadal, 2007), which may lead to a widening regional gap. Krakover (2004) concludes that tourism's influence over regional development, particularly regarding the regional gap issue, is one of today's most intricate research topics.

Severe and increasing regional inequality still exists in numerous countries worldwide (Deller, 2010). In China, there are huge regional gaps that reflect gradual reductions in development levels from eastern to western regions and from coastal to inland regions in terms of the real GDP per capita and per capita consumption expenditures of the Chinese provinces (Wen \& Sinha, 2009). This polarized development has become a serious threat to China's social stability, prompting other instances of inequality in areas such as medical and educational opportunities. China is seeking ways to narrow the continuingly widening regional gaps, and whether tourism development is a viable and effective way to achieve this goal must be empirically tested.

The aim of this study is to establish a theoretical link between tourism development and narrowing regional income inequality, and provide empirical evidence based on a case with 30 Chinese provinces. It makes four contributions to the literature. First, it provides a theoretical foundation for and a statistical analysis of tourism development's effect on regional income inequality. Second, it examines both international and domestic tourism to assess which is a more effective factor in reducing regional inequality. To the best of our knowledge, this is the 
first attempt to compare the regional effects of domestic and international tourism within a theoretical framework of conditional convergence. Third, this study is the first attempt to apply a spatiotemporal model in tourism accounting for both spatial and temporal dependence. In addition, the use of panel data allows for local estimation of spatial models at a province or country level, which is not possible using cross-sectional data due to a limited sample size. Moreover, a dynamic panel model is able to capture the heterogeneity across cases and over time, as well as the heterogeneity in the regression coefficients. Fourth, this study contributes to the general literature by extending the local estimation to a dynamic spatial panel context. It is demonstrated that local spatial analysis is a useful tool to examine economic convergence. Particularly, at a regional level with a small number of cases, the local dynamic spatial panel is an effective method. Based on the more advanced methodology, this study sheds new light on the contribution of tourism development on reducing income inequality with cross-regional spillover effects being taken into account. Specifically, it provides insight into each region's unique situation of tourism-led economic growth, and therefore enhances our knowledge about the regional tourism development in China.

\section{LITERATURE REVIEW}

\section{Tourism Development and Regional Inequality: A Theoretical Foundation}

Tourism is closely related to a number of other economic sectors such as agriculture, construction and retailing, and thus its development has potential to generate positive externalities on the rest of the economy. Tourism development can also promote the productivities of other industries through industrial substitution and integration, and lead to structural change (Kadiyali \& Kosová, 2013).

Various studies (e.g. Nelson \& Pack, 1999; Pender, 2003) show that the resource shift or structural change from traditional sectors to specific dynamic sectors with faster productivity growth and more productive technologies has been an extra source of aggregate productivity growth in addition to any sectoral productivity growth in many countries. These are called 'structural bonus hypotheses'. Fan, Zhang, and Robinson (2003) point out that China has significant potential for efficiency improvement via continuous structural change given that there are large differences in both labor and capital productivity among various sectors. They estimate that approximately $17 \%$ of economic growth in China over the 1978-1995 period can be attributed to structural change. During the structural change, resources (mainly labor) shift from lower to higher productivity sectors, i.e., from agriculture to urban manufacturing, urban services and rural enterprises. Therefore, structural change prompted by tourism development has potential to promote productivity and economic growth. 
The structural change prompted by tourism development and its effect on productivity and economic growth may show regional differences due to differing levels of economic development and the industrial switching cost. Chenery, Robinson, and Syrquin (1986) propose that economic structural change affects productivity and economic growth more prominently in less developed economies, because less developed economies are accompanied by wider productivity disparities between industries (McMillan \& Rodrik, 2011).

Similarly, the growth pole theory addresses that priority given to industries or sectors with higher backward and forward linkages can be a major force for growth of economic output and income in developing countries or less developed regions, and output and employment will grow more rapidly than if these sectors are not given special favors (Perroux, 1988). On this basis, tourism has the potential to be targeted as the leading industry in many peripheral areas, in the hope of reducing spatial economic disparity.

Tourism spillovers also tend to balance regional income inequalities. "Tourism spillover effects" refer to the indirect or unintentional effects that a region's tourism industry exerts on tourist flows to other regions (Yang \& Wong, 2012). Lazzeretti and Capone (2009), Yang and Wong (2012), and Yang and Fik (2014) have empirically identified the spillover effects in regional tourism flows or growth. By using the method of Local Indicators of Spatial Association, Majewska (2015) also identifies and empirically measures the inter-regional effects of spatial agglomeration in tourism via considering the occurrence and strength of geographic spillover effects in Poland. In common with other economic sectors, tourism generates spillover effects from higher productivity regions to lower productivity regions, through a combination of labor movements, demonstration effects and competition effects (Blomstrom \& Kokko, 1997). In addition to productivity spillovers, tourism also generates demand-side spillovers due to the fact that some tourists travel to multiple neighboring destinations (Yang \& Wong, 2012; Lue, Crompton, \& Fesenmaier 1993) and attend megaevents (Deccio \& Baloglu, 2002). Supply-side spillovers are also evident due to the prospects for market access and joint promotional activities (Yang \& Wong, 2012; Gooroochurn \& Hanley, 2005). With the rapid development of civil aviation and high-speed rail, tourism spillover effects will be more significant and far reaching still. Moreover, Yang and Fik (2014) also argue that the spatial competition among regional governments increases the incentives to support tourism, which in turn leads to a higher level of spillovers in regional tourism growth especially for those under-developed regions.

It has been found that the effects of tourism present spatial heterogeneity across regions. There are two types of spatial heterogeneity: heterogeneity in spatial dependence and heterogeneity at the steady state. Heterogeneity in spatial dependence is observed when the regression coefficients of spatially lagged terms vary across regions, which causes a different effect of tourism. This heterogeneity can be captured by local estimation methods such as 
geographically weighted regression (GWR) (Páez, Uchida, \& Miyamoto, 2002) and the spatial autoregressive local estimation (SALE) (Pace \& LeSage, 2004). Heterogeneity at the steady state is caused by unobserved variables that are destination-specific and correlated with independent variables (Elhorst, Zandberg, \& De Haan, 2013). For example, the natural endowment of tourism destinations, which is time-invariant and correlated with tourism income, may vary across provinces. This heterogeneity can be measured by the fixed effect with a panel data approach. However, so far all the studies in tourism spatial economics have been based on cross-sectional data. Omitting the heterogeneity effects may cause biased estimation (Elhorst et al., 2013). The present study thus aims to bridge this gap.

\section{Tourism and Economic Growth: Concepts and Measurement}

The theoretical foundation described above and the model of tourism's effect on regional income inequality empirically tested below originated from the theories and literature on tourism and economic growth. Therefore, it is necessary to provide a brief overview of the research progress in this field.

The majority of the empirical studies in this area are based on tourism-led growth (TLG) or the tourism exports $\rightarrow$ capital goods imports $\rightarrow$ growth (TKIG) hypothesis (Chou, 2013; Cortés-Jiménez, Nowak, \& Sahli, 2011), which originates from theory of export, and international tourism is treated as a kind of export. The most frequently used methods are the Granger causality test and co-integration analysis, and the main criticism faced by the TLG and TKIG studies is their reliance on the Granger causality test, which only represents the secessionist's view of causation and does not necessarily suggest the real cause-effect relationship (Song, Dwyer, Li, \& Cao, 2012). Other studies are based on neoclassical economic growth theory and the augmented Solow model, including tourism proxies as a separate input factor or international inbound tourism as a component of exports into this model, which is rather questionable. Finally, most previous studies only analyze the relationship between international tourism and economic growth, which neglects the contribution of domestic tourism to economic growth (Cortés-Jiménez, 2008). Apart from the data unavailability problem, another reason for omitting domestic tourism is that its effect on economic growth cannot be explained by the TLG hypothesis framework or as part of international trade.

\section{Tourism and Regional Inequality}

The limited literature on this topic conveys two contrasting ideas. First, tourism reduces regional inequality. Poor peripheral areas usually have a surplus of tourism attractions, which tends to distribute development away from industry centers toward a country's underdeveloped regions. Second, tourism enlarges regional inequality. The uneven tourism distribution includes one or several tourism-rich core regions and several less-developed tourism regions. Thus, 
Krakover (2004) argues that the relationship between tourism and regional inequality is country specific and dependent on many other factors.

Göymen (2000) and Seckelmann (2002) argue that the inequality among various areas in Turkey is enlarged by international tourism development, as developed and coastal locations receive more tourism-related investments and more superior policies. As a result, these regions have grown much faster, and therefore regional inequality is further enlarged. Similarly, in Greece, more funds are distributed to areas with higher levels of tourism-based economic development, widening the regional gaps (Liargovas, Giannias, \& Kostandopoulos, 2007). In contrast, based on a comparison between the center and the peripheries in Israel, Krakover (2004) notes that Israel's tourism success in reaching regional balanced economic development is due to special situations, namely, the size of the country, government policies and security issues. Based on a conditional convergence model, Proenca and Soukiazis (2008) find that international tourism has a prominent influence on reducing regional gaps among different locations in Spain, Italy, Greece and Portugal. Similarly, Soukiazis and Proenca (2008) show that tourism (accommodation capacity as a proxy) increases the convergence rate within Portugal's NUTS-2 and NUTS-3 regions.

In China, Wen and Tisdell (1996) use cross-sectional data to compare the regional distribution of inbound tourism and that of socio-economic variables and find that the concentration of the former is higher than that of the latter. This means that China's uneven regional development is accelerated by tourism development. From a dynamic perspective, Wen and Sinha (2009) use the Gini coefficient method and find that both the spatial distribution of international tourism demand and tourism supply exhibit a decreasing trend. They argue that this phenomenon is promising in relation to narrowing China's severe regional disparity among coastal and inland regions.

It is common knowledge that in many countries, domestic tourism is dominant over international flows in terms of both the size and the economic contribution. Therefore, domestic tourism has more potential to contribute to reducing disparities in less developed economies (Massidda \& Etzo, 2012). However, only two studies mention or test the possible effect of domestic tourism development on regional income inequality. Given domestic tourism's rapid development, Seckelmann (2002) proposes that southeastern Turkey and other less-developed regions with more natural and historical resources attract more domestic tourists, which is considered to be an instrument to achieve balanced regional development. Haddad, Porsse, and Rabahy (2013) apply an input-output model in the first attempt to empirically study the regional effect of domestic tourism, and conclude that domestic tourism narrows regional disparity in Brazil.

The literature review indicates that tourism does have the potential to affect regional inequality, but a number of limitations are also identified. First, no research provides both a 
theoretical foundation for and a statistical analysis of the effect of tourism development on regional income inequality. Second, although many studies stress that tourism could affect regional inequality, most of them focus only on international tourism, while domestic tourism, which constitutes a larger proportion of the total tourism revenue in big countries such as the US and China, is underestimated and even neglected, with only two exceptions. Third, no empirical study compares domestic and international tourism in terms of their effects on regional inequality. Fourth, the literature, which only illustrates the regional distribution of tourism development via descriptive analysis, does not provide statistical evidence of the casual relationships between tourism and regional inequality.

\section{METHODOLOGY}

\section{Conditional Convergence Framework}

Convergence represents the tendency of different economies to achieve equivalent levels of economic development. Unlike absolute $\beta$-convergence, in which all economies converge to the same steady state, in conditional $\beta$-convergence economies converge to different steady states by allowing different levels of technology, saving propensities and rates (Proenca \& Soukiazis, 2008; Sala-i-Martin, 1996). Conditional convergence originates from endogenous growth theory, which happens to lie in some included structural factors (e.g. human capital accumulations and technological progress), promoting economic growth with an increasing-returns-to-scale effect (Sala-i-Martin, 1994). A simplified conventional convergence equation can be written as Equation (1):

$$
\ln \left(y_{i, t}\right)=\gamma_{i}+b \ln \left(y_{i, t-1}\right)+c_{j} \ln X_{i, t}^{j}+u_{i, t}
$$

where $y_{i, t}$ is the output per capita of the $i$ th economy at time $t$ and $X_{i, t}^{j}$ is a vector of $j$ factors that control different growth rates across various economies at time $t$. The variables with increasing returns to scale must be included in $X_{i, t}^{j} \cdot \gamma_{i}$ represents different steady economy values of the per capita output dependent on the above $j$ control variables and the initial output per capita. $b-1$ is the absolute convergence coefficient, $c$ is the estimation coefficients for the $j$ control variables and $u$ is the stochastic error. If $b-1<0, \gamma_{i}=\gamma(\gamma$ is the common steady state, which is a constant term) and $c_{j} \neq 0$, conditional convergence happens. Otherwise, if $b-1<0, \gamma_{i}=\gamma$ and $c_{j}=0$, the convergence is absolute instead of conditional.

Considering the explanatory variables in the economic growth model (Mankiw, Romer, $\&$ Weil, 1992), Equation (1) can be specified as the following form:

$$
\ln \left(y_{i, t}\right)=\gamma_{i}+b \ln \left(y_{i, t-1}\right)+a_{1} \ln \left(s_{i, t}\right)+a_{2} \ln \left(n_{i, t}+g+\delta\right)+a_{3} \ln \left(h_{i, t}\right)+u_{i, t}
$$


where $y_{i, t}$ is the real GDP per capita at constant prices, $s_{i, t}$ is the ratio of real capital stock to real GDP, $g$ is the growth rate of technology progress, $\delta$ is the rate of capital depreciation, $g+$ $\delta$ is equal to 0.05 according to Mankiw et al. (1992) and Proenca and Soukiazis (2008), $n_{i, t}$ is the labor growth rate (the natural population growth rate) and $h_{i, t}$ is the human capital (usually seen as an input factor with increasing returns to scale).

\section{Tourism Augmented Conditional Convergence Framework}

The conditional convergence model originates from the Solow (1956) growth model, in which technological change is exogenous; that is, unaffected by a country's tourism development. Yet the 'new' growth theories suggest that technological/productivity change is endogenous. We propose that tourism development potentially affects economic growth through its effect on technological or productivity change, as discussed in the literature review.

Based on the model developed by Solow (1956) and Mankiw et al. (1992), we describe the mathematical analysis of how tourism is added into a growth model as a conditional convergence factor. Learning from the analytical method used by Islam (1995), Solow's model takes the rate of savings and population growth as exogenous and considers three types of input: physical capital, human capital and labor. We also assume that the economic growth and conditional convergence follow the constant returns to scale production function. The revised Cobb-Douglas production function used by Mankiw et al. (1992) (hereafter referred to as the MRW model) is expressed as Equation (3):

$$
Y(t)=K(t)^{\alpha} H(t)^{\beta}(A(t) L(t))^{1-\alpha-\beta}
$$

where $Y(t)$ is the output, $K(t)$ is the physical capital investment, $H(t)$ is the human capital and $L(t)$ is the labor input. $A(t)$ measures the cumulative effect of generalized technical progress over time. $\alpha$ and $\beta$ represent exogenously given parameters, where $0<\alpha<1,0<\beta<1$ and $0<\alpha+\beta<1 . A(t) L(t)$ represents the effective labor. $L(t)$ and $A(t)$ are assumed to grow exogenously at rates $n$ and $g$, and the number of effective units of labor, $A(t) L(t)$, grows at rate $n+g$.

Since tourism is an important information and technology source for getting access to foreign knowledge, for the generation of new products and increasing the quality of existing ones, it offers the prospect of improving firms' efficiency and competitiveness, thereby enhancing regional productivity at an aggregate level (Hovhannisyan, 2013; Marrocu \& Paci, 2011). According to Nicita and Olarreaga (2007), this mechanism is reinforced when tourists come from relatively richer countries or regions and exhibit preferences for higher quality goods compared to local consumers. To augment the MRW model, we consider the effect of tourism development on generalized technical progress, as previously discussed (here, generalized technological progress is endogenous), and thus the generalized technological progress equation is written as Equation (4): 


$$
A=A(0) e^{g t} T R^{\theta}
$$

where $g$ is the rate of technical progress, $T R$ represents the total tourism development and $\theta$ is the elasticity of tourism development on technical progress.

The model assumes that a constant fraction of output, $s$, is invested. $y=Y / A L, k=$ $K / A L$ and $h=H / A L$ represent the output of the unit effective labor, physical capital of the unit effective labor and human capital of the unit effective labor, respectively. On this basis, we obtain the dynamic expression of $k(t)$ and $h(t)$, as Equations (5) and (6):

$$
\begin{aligned}
& \widetilde{k(t)}=s_{k} y(t)-(n+g+\delta) k(t) \\
& \widetilde{h(t)}=s_{h} y(t)-(n+g+\delta) h(t)
\end{aligned}
$$

where $\delta$ is the rate of depreciation.

When the economy reaches the steady state, $\widetilde{k(t)}=0$ and $\widetilde{h(t)}=0$. According to Equations (5), (6) and (3), we can obtain $k^{*}(t)$ and $h^{*}(t)$ representing $k$ and $h$ in the steady state.

$$
\begin{aligned}
& k^{*}=\left(\frac{s_{k}{ }^{1-\beta} s_{S_{h}}{ }^{\beta}}{n+g+\delta}\right)^{1 /(1-\alpha-\beta)} \\
& h^{*}=\left(\frac{s_{k}{ }^{\alpha} s_{h}{ }^{1-\alpha}}{n+g+\delta}\right)^{1 /(1-\alpha-\beta)}
\end{aligned}
$$

Substituting (4), (7) and (8) into the production function (3), then taking the natural logarithm on both sides of the equation, we obtain the following expression:

$\ln \left[\frac{Y(t)}{L(t)}\right]=\ln A(0)+g t-\frac{\alpha+\beta}{1-\alpha-\beta} \ln (n+g+\delta)+\frac{\alpha}{1-\alpha-\beta} \ln \left(s_{k}\right)+\frac{\beta}{1-\alpha-\beta} \ln \left(s_{h}\right)+\theta \ln (T R)$

Due to the lack of data on human capital investment rates, we use an alternative variable, the stock of human capital, to represent them (Mankiw et al., 1992). According to Equations (8) and (9), we can obtain the regression model of output per capita against physical capital, population growth rate, human capital stock and total tourism receipts as follows:

$$
\ln \left[\frac{Y(t)}{L(t)}\right]=\ln A(0)+g t+\frac{\alpha}{1-\alpha} \ln \left(s_{k}\right)-\frac{\alpha}{1-\alpha} \ln (n+g+\delta)+\frac{\beta}{1-\alpha} \ln \left(h^{*}\right)+\theta \ln (T R)
$$

Let $y^{*}$ represent the output of the unit effective labor in the steady state, which is decided by and calculated from Equation (10), and let $\ln (y(t))$ represent the output level of the unit effective labor at time $t$. In the vicinity of the steady-state level, the economic convergence speed can be expressed as:

$$
\frac{d \ln (y(t))}{d t}=\beta\left[\ln \left(y^{*}\right)-\ln (y(t))\right]
$$

where $\beta=(n+g+\delta)(1-\alpha-\beta)$, representing the convergence speed. It refers to the average speed at which different regional economies (with different GDPs per capita) converge to their own steady states (long-run economic level) per time unit $t$ (Sala-i-Martin, 1996). According to Equation (11), we obtain the following expression:

$$
\ln (y(t))=\left(1-e^{-\beta t}\right) \ln \left(y^{*}\right)+e^{-\beta t} \ln (y(0))
$$


where $y(0)$ is the initial output of unit effective labor. If we subtract $\ln (y(0))$ on both sides of Equation (12), we obtain the following expression:

$$
\ln (y(t))-\ln (y(0))=\left(1-e^{-\beta t}\right) \ln \left(y^{*}\right)-\left(1-e^{-\beta t}\right) \ln (y(0))
$$

Substituting $\ln \left(y^{*}\right)$ calculated from Equation (10) into the above expression (13), we obtain the following convergence model:

$$
\begin{aligned}
& \ln (y(t))-\ln (y(0))=\left(1-e^{\beta t}\right) \ln A(0)+\left(1-e^{\beta t}\right) g t+\left(1-e^{\beta t}\right) \frac{\alpha}{1-\alpha} \ln \left(s_{K}\right)-(1- \\
& \left.e^{\beta t}\right) \frac{\alpha}{1-\alpha} \ln (n+g+\delta)+\left(1-e^{\beta t}\right) \frac{\beta}{1-\alpha} \ln (h)+\theta\left(1-e^{\beta t}\right) \ln (T R)-\left(1-e^{\beta t}\right) \ln (y(0))
\end{aligned}
$$

Assume that technology can flow freely among a country's provinces and cities, so that when different provinces and cities have the same exogenous technological progress rate and the time intervals are consistent, gt can be seen as the time effect not varying across individual regions. Meanwhile, assuming that all provinces and cities have the same initial generalized technical progress level $A(0),\left(1-e^{\beta t}\right) \ln A(0)$ can be seen as an individual effect not varying over time.

Based on Equation (14) and given that different economies have different steady-state levels predicted by the Solow model (Mankiw et al., 1992), individual economies eventually converge to different steady-state levels. Then the tourism augmented conditional convergence model can be specified as follows:

$\ln \left(y_{i, t}\right)=\gamma_{\mathrm{i}}+b \ln \left(y_{i, t-1}\right)+a_{1} \ln \left(s_{i, t}\right)+a_{2} \ln \left(n_{i, t}+g+\delta\right)+a_{3} \ln \left(h_{i, t}\right)+a_{4} \ln \left(T R_{i, t}\right)+u_{i, t}$

Before incorporating spatial effects into the model, the differences between Equations (9) and (15) should be noted. Equation (9) is valid only if the economy is in its steady state or if deviations from the steady state are random. Equation (15) has the advantage of explicitly considering out-of-steady-state dynamics. China is not in its steady state because $\widetilde{k(t)}$ and $\widetilde{h(t)}$ are not in the vicinity of zero. Therefore, Equation (15) is considered as the convergence framework for this study.

\section{Spatiotemporal Autoregressive Model}

Spatial effects are relatively unexplored in the convergence literature (James \& Campbell, 2014). However, it is found that their influence on the convergence results is great, and neglecting spatial effects clouds the causes, speed and nature of the convergence process (Islam, 2003; James \& Campbell, 2013; 2014). Previous literature shows that when spatial effects are incorporated into the convergence model, they tend to be significant and strongly influence the convergence speed (James \& Campbell, 2013; Rey \& Montouri, 1999). Most recently James and Campbell (2014) examine the impact of geographic spatial effects on 
conditional convergence in the US from 1970 to 2004, and model diagnostics show that a spatial autoregressive (SAR) conditional convergence model is more appropriate than a standard ordinary least squares (OLS) model. OLS and SAR models are compared and the results show that convergence models are sensitive to spatial effects and spatial models consistently outperform their OLS counterparts.

To account for spatial effects in tourism and economic growth, spatial Durbin models (SDM) have been used to capture the spatial interdependence in both dependent and explanatory variables (Yang \& Fik, 2014). Moreover, SDMs may reduce estimation biases amplified by omitted variables due to the inclusion of the spatially lagged dependent variable (LeSage \& Pace, 2009). A SDM can be written in the vector form as follows:

$$
Y=\rho W Y+X \beta+W X \theta+\varepsilon
$$

where $Y$ is an $N \times 1$ vector of income in a sample of $N$ regions; $X$ is an $N \times k$ matrix of explanatory variables; $W$ represents the row standardized $(N \times N)$ spatial weight matrix; $\beta, \rho$, and $\theta$ are the vectors of spatial parameters to be estimated; and $\varepsilon$ is the error term. This study extends the SDM through a dynamic panel approach specifying a SDM-based spatiotemporal model. This is also an extension from the SAR-based spatiotemporal model proposed by Lee and $\mathrm{Yu}$ (2010) and Elhorst et al. (2013) by incorporating spatial lags of explanatory variables. The motivations are threefold. Firstly, the heterogeneity at the steady state can be measured by fixed spatial effects. It also implies a different steady state for each province. Secondly, in addition to spatial dependence, temporal dependence is incorporated to improve the explanatory power of the model and further reduce the bias caused by omitted variables. Finally, local estimation becomes possible for a small sample with limited regions.

With the inclusion of spatial lags of dependent and explanatory variables, Equation (15) can be rewritten in the following vector form as Equation (17):

$$
Y_{t}=\tau Y_{t-1}+\rho W Y_{t}+X_{t} \beta+W X_{t} \theta+\mu+\varepsilon
$$

where $Y_{t}$ denotes an $N \times 1$ vector of income at time $t$ in a sample of $N$ regions; $W$ is a spatial weights matrix; $X_{t}$ is an $N \times k$ matrix of exogenous explanatory variables; $\mu$ is a vector with spatial fixed effects; and $\varepsilon$ is an error term. Correspondingly, the convergence speed can be calculated as $\beta=-\ln (\tau)$ (Yu \& Lee, 2012). If the convergence without tourism being considered as a conditional convergence factor is slower than the convergence with tourism being added to the convergence model, then the conclusion can be drawn that tourism reduces regional income inequality.

\section{Local Estimation}


The heterogeneity in spatial dependence causes structural instability in the parameters, that is, the spillover effects may vary across regions. Differing to the global model where the regression coefficients are location invariant, the coefficients are allowed to vary from region to region in local estimation which is underpinned by spatial dependency between neighbors. Local estimation is therefore particularly useful for identifying the heterogeneity and providing practical implications by visualizing the local regression coefficients (Wheeler \& Tiefelsdorf, 2005). Different approaches have been proposed to estimate the parameters of local models such as GWR (Páez et al., 2002; Yang \& Fik, 2014) and SALE (Pace \& LeSage, 2004). However, the local estimates could be very sensitive to local model specifications such as the number of neighbors to be included in a local model. Páez et al. (2011) recommend a minimum sample size of 160 for GWR. Although this issue can be partially eased with the SALE or GWSDM method (Yang \& Fik, 2014) by including a spatial lag of the dependent variable which in effect increases the sub-sample size of the local model, they are still unviable for local estimation with a limited number of regions. To address this issue, the present study extends the SALE approach to a dynamic panel context by incorporating both temporal and spatial lags of the dependent variable into the local model, which significantly expands the sub-sample size. With this extension, it becomes possible to conduct an analysis at the province or country level where only limited cross-sectional units are available.

Based on the global model (Equation 17), a local model can be specified for region $i$ in the sample:

$$
U(i) Y_{t}=\tau U(i) Y_{t-1}+\rho U(i) W Y_{t}+U(i) X_{t} \beta+U(i) W X_{t} \theta+U(i) \mu+U(i) \varepsilon
$$

where U(i) denotes an $N \times N$ diagonal spatial weight matrix for region $i$. It assigns weights of one to the $m$ nearest neighbors of region $i$, and zero to the other regions in the sample (Ertur, Gallo, \& LeSage, 2007). This essentially extracts a sub-sample for each local model. The models can then be estimated recursively (Pace \& LeSage, 2004).

\section{Data Source and Variable Descriptions}

To estimate Equations (2) and (3), this study uses annual data from 30 provinces in China from 1997 to 2010. Due to the unavailability of related data for the Municipality of Chongqing, it is excluded from this study. With regard to the measurement of key variables, $y_{i, t}$ is measured by real GDP per capita in constant prices of 1991 (in Chinese yuan), $s_{i, t}$ ratio of real capital stock to real GDP (\%), $n_{i, t}$ natural population growth rate $(\%), h_{i, t}$ average years of schooling in the population, and data for these variables are from the China Statistical Yearbook; tourism variables including total tourism receipts $T R_{i, t}$, domestic tourism receipts $D T R_{i, t}$, international tourism receipts $I T R_{i, t}$ (all in constant prices of 1991, million yuan), and total hotel room number are from the China Statistical Yearbook on Tourism. The descriptive 
statistics for the variation over provinces/municipalities and time (1997-2010) are presented in Table 1. The statistics show evidence of considerable variations for most variables used in this study.

Table 1. Descriptive Statistics: Variations over Provinces/Municipalities and Time (1997-2010)

\begin{tabular}{lccccccc}
\hline Variable & Observations & Mean & S.D. & $\begin{array}{c}\text { S.D. } \\
(\mathrm{BG})\end{array}$ & S.D. (WG) & Min & Max \\
\hline $\ln \left(y_{i, t}\right)$ & $420(\mathrm{n}=30)$ & 8.614 & 0.699 & 0.527 & 0.469 & 6.975 & 10.323 \\
$\ln \left(s_{i, t}\right)$ & $420(\mathrm{n}=30)$ & -0.742 & 0.331 & 0.190 & 0.273 & -1.487 & 0.032 \\
$\ln \left(n_{i, t}+g+\delta\right)$ & $420(\mathrm{n}=30)$ & -2.237 & 0.340 & 0.311 & 0.147 & -3.474 & -0.817 \\
$\ln \left(h_{i, t}\right)$ & $420(\mathrm{n}=30)$ & 2.163 & 0.087 & 0.079 & 0.038 & 1.846 & 2.460 \\
$\ln \left(T R_{i, t}\right)$ & $420(\mathrm{n}=30)$ & 4.804 & 1.442 & 1.271 & 0.718 & 0.304 & 7.563 \\
$\ln \left(D T R_{i, t}\right)$ & $420(\mathrm{n}=30)$ & 4.691 & 1.474 & 1.280 & 0.764 & -0.724 & 7.492 \\
$\ln \left(I T R_{i, t}\right)$ & $420(\mathrm{n}=30)$ & 2.162 & 1.701 & 1.651 & 0.505 & -3.183 & 5.921 \\
\hline & & & & & & & \\
\hline
\end{tabular}

\section{EMPIRICAL RESULTS}

\section{Descriptive Evidence}

When the absolute convergence occurs, decreased regional income inequality is reached. However, some economies may reach the steady states at a pretty low economic level, thus absolute convergence does not necessarily happen but conditional convergence occurs. Conditional convergence may still imply that the regional income inequality is narrowed, subject to the general level of the regional development at the steady state. The spatial local model used in this study, a developed conditional convergence model, takes account of the regional development level by incorporating the spatial heterogeneity. In addition, this study employs both the conditional convergence model and Gini coefficient analysis (Wen \& Tisdell, 1996; Wen \& Sinha, 2009) in order to well consider the importance of general regional development level in the convergence phenomenon. 


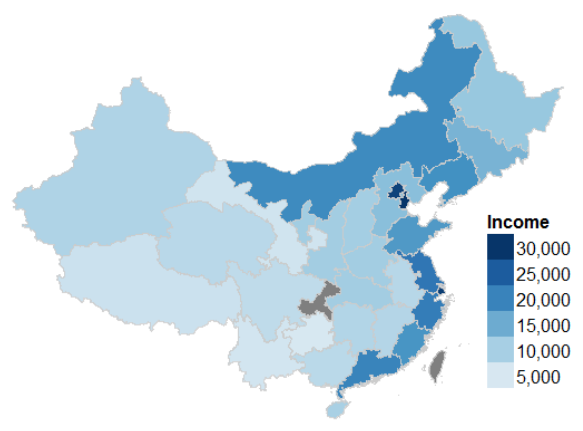

Figure 1. Regional Distribution of Income in China (Real GDP per capita in 2010)

In China, high regional inequality is most evident among the three economic areasthe eastern, central and western regions - in terms of real GDP per capita (as shown in Figure 1). Therefore, narrowing the regional disparity among the three economic regions is the key issue for China's balanced regional development. Figure 2 presents the evolution and trends of tourism development in the three economic areas, in an attempt to detect tourism's potential in reducing regional inequality in China. It shows that the proportion of total tourism receipts in the eastern region decreases from about $72 \%$ in 1997 to $60 \%$ in 2010 while the proportions in the central and western regions show a corresponding upward trend. A similar trend can also be seen with hotel room numbers and domestic tourism receipts. However, the convergence trend among the three economic regions is not as evident as with international tourism. In China, domestic tourism is the dominant type in all the three regions, in terms of both the size and the growth rate. Domestic tourism distribution is predominantly determined by local and neighboring regions' infrastructure development, natural and cultural tourism resources and the income level, while the degree of openness and historical policy are important for the inbound tourism distribution. Plenty of less developed provinces with rich natural and cultural tourism resources regard tourism, especially domestic tourism, as their important source of income, and they position the tourism industry as the pillar industry or priority industry to be developed. Therefore, the spatial distribution of domestic tourism is less imbalanced than that of international tourism, thus the impact of domestic and international tourism distribution on regional economic inequality may be different. 

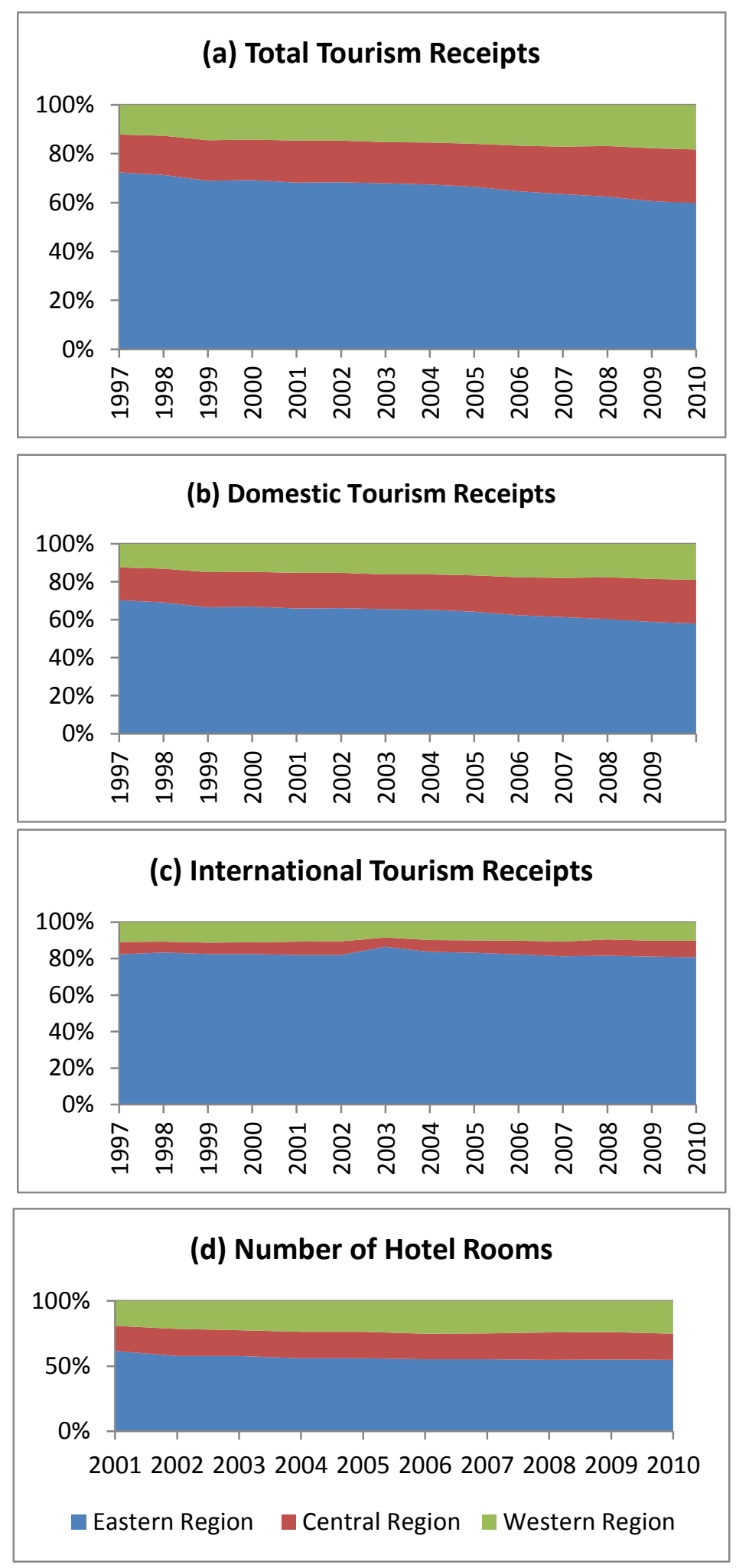

Figure 2. Regional Distribution of Tourism Development in China (1997-2010)

Note: China's Eastern region includes 11 provinces (Liaoning, Hebei, Beijing, Tianjin, Shandong, Jiangsu, Shanghai, Zhejiang, Fujian, Guangdong and Hainan); its Central region includes 8 provinces: Heilongjiang, Jilin, Shanxi, Henan, Hubei, Hunan, Anhui 
and Jiangxi; its Western region includes 12 provinces: Inner Mongolia, Ningxia, Shaanxi, Gansu, Xinjiang, Qinghai, Sichuan, Chongqing, Tibet, Yunnan, Guizhou and Guangxi.

The Gini coefficient is a measure of statistical dispersion and inequality intended to demonstrate imbalanced spatial distribution, which means the larger the Gini coefficient is, the larger the regional disparity becomes. We calculate the evolution of Gini coefficients on the regional tourism and regional economic development of 31 provinces in China from 1997 to 2010 to understand the patterns of tourism and economic spatial distributions. As Figure 3 shows, the Gini coefficient of GDP per capita displays a slight upward trend from 1997 to 2005 and then follows a downward trend afterwards. The Gini coefficients of tourism receipts and hotel room numbers both present an overall decreasing trend throughout the whole sample period. Figure 3 demonstrates that the tourism imbalanced spatial distribution has declined with the degree of China's imbalanced regional developments, indicating a positive relationship between tourism development and decreased regional inequality.

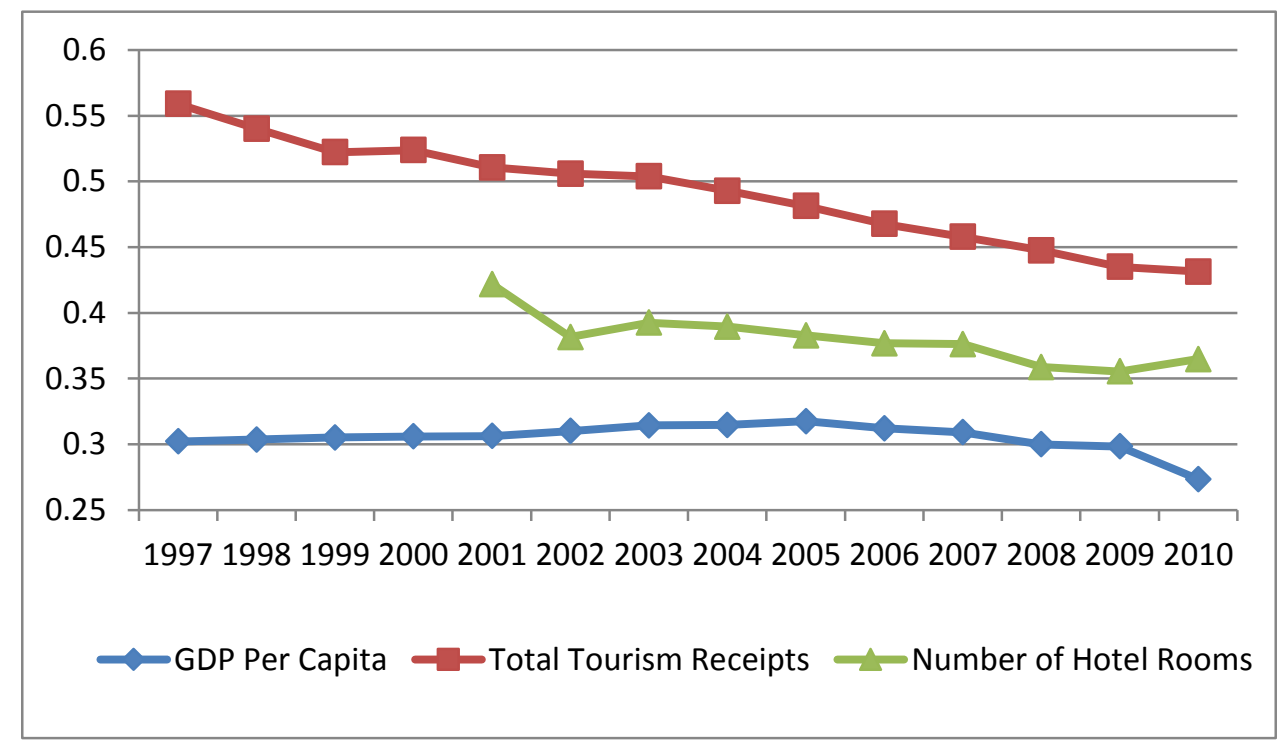

Figure 3. Gini Coefficients for GDP per capita, Total Tourism Receipts and Number of Hotel Rooms in China (at Provincial Level, 1997-2010)

\section{Estimates of Global Models}

To test whether tourism development is an effective conditional convergence factor, this study estimates four different models with MATLAB program. First, the conditional convergence model without the tourism development variable (Model 1) is estimated, in which only the other key control variables are contained. Second, the conditional convergence model including a tourism development variable is estimated, in which tourism development (using total tourism receipts and the spatial lag of total tourism receipts as a proxy) is included as a 
conditional convergence factor (Model 2). Third, given that in a big country like China domestic and international tourism have different scales, annual growth rates, spatial distributions and regional effects, they may have extremely different patterns of effects on economic growth and regional income inequality. To test which type is more efficacious, this study further estimates another two conditional convergence models that use international tourism (using international tourism receipts and the spatial lag of international tourism receipts as a proxy, Model 3) and domestic tourism (using domestic tourism receipts and the spatial lag of domestic tourism receipts as a proxy, Model 4) as conditional convergence factors, respectively.

The specification of the spatial weight matrix ( $W$ in Equation 17) is essential in spatial modeling, as different weights may generate different estimates. Following the suggestion by Elhorst et al. (2013), the residual variance is used as a criterion to select the weight matrix. The distances between provinces are measured by the Great Circle distance between their capital cities. The residual variances based on weight matrices of inverse distance band (a distance band to ensure that each province has at least one neighbor), and $m$ (from 1 to 10) nearest neighbors are calculated for each model specification. As shown in Figure 4, the inverse distance band weight matrix generally generates the lowest residual variances. It is therefore selected for the model estimation.

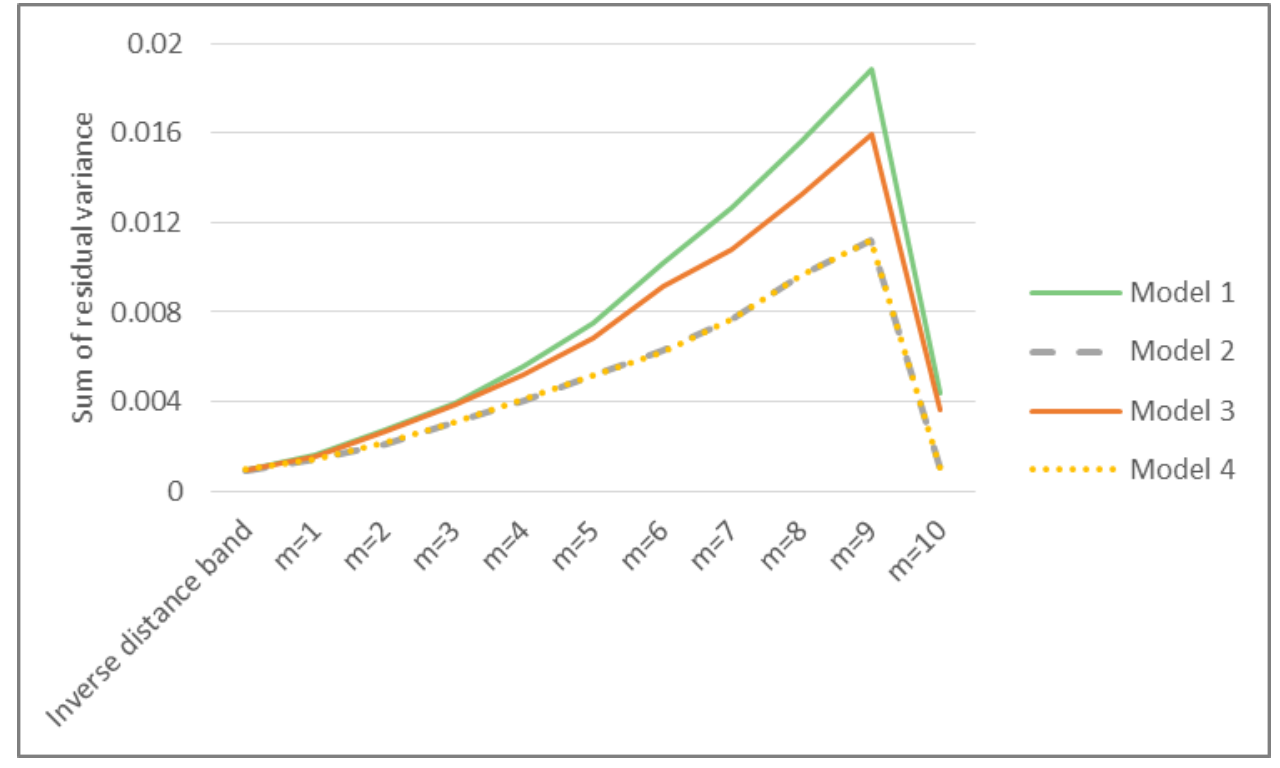

\section{Figure 4. Sum of Residual Variance against Different Spatial Weight Matrices}

The model estimation results are presented in Table 2. Both spatial and temporal lags of income are significant and positive across all the model specifications. Ratio of real capital stock to real GDP (lns) and its spatially lagged term are significant as well. Yet the negative signs of $\mathrm{W}^{*}$ Ins imply a competition effect on capital. While the human capital (lnhc) is non- 
significant in its own province, human capital from neighbors positively contributes to the income of a province. This indicates a complementary effect of labor between regions.

In terms of the impact of tourism on income, all the tourism revenue variables in the own regions are significant and positive. Domestic tourism revenue (lnDTR) has a larger coefficient compared to international tourism revenue (lnITR). The spatial lag of total tourism revenue shows a negative influence on income, which suggests a competition effect across provinces.

In contrast to the convergence speed when the factor of tourism development is excluded (Model 1), it is found that the inclusion of the tourism factor (Model 2) increases the convergence from a rate of 0.0796 to 0.1157 . Specifically, domestic tourism (Model 4) creates a higher boost compared to international tourism (Model 3). To examine the stationarity of the data generating process (DGP), similar to Elhorst (2012), the conditions that $|\tau|<1-\rho w_{\text {max }}$, if $\rho \geq 0 ;|\tau|<1-\rho w_{\text {min }}$, if $\rho<0$ should be satisfied, when the weight matrix $W$ is rownormalized, and the rows and columns of $W$ and $(I-\rho W)^{-1}$ are uniformly bounded. The results suggest that the DGPs are stationary as the conditions are met $\left(|\tau|<1-\rho w_{\text {max }}, \rho>0\right.$, $w_{\text {max }}=1$ ) for all the models.

Table 2. Estimates of global models

\begin{tabular}{|c|c|c|c|c|}
\hline Variable & Model 1 & Model 2 & Model 3 & Model 4 \\
\hline $\ln \mathrm{Y}(\mathrm{t}-1)$ & $\begin{array}{l}0.923 * * * \\
(41.529)\end{array}$ & $\begin{array}{l}0.891 * * * \\
(36.487)\end{array}$ & $\begin{array}{l}0.919 * * * \\
(41.394)\end{array}$ & $\begin{array}{l}0.902 * * * \\
(35.793)\end{array}$ \\
\hline $\ln s$ & $\begin{array}{l}0.061 * * * \\
(5.833)\end{array}$ & $\begin{array}{l}0.052 * * * \\
(4.921)\end{array}$ & $\begin{array}{l}0.059 * * * \\
(5.650)\end{array}$ & $\begin{array}{l}0.056 * * * \\
(5.260)\end{array}$ \\
\hline $\ln (n+g+d)$ & $\begin{array}{l}-0.034 * * \\
(-2.279)\end{array}$ & $\begin{array}{l}-0.025 \\
(-1.634)\end{array}$ & $\begin{array}{l}-0.032 * * \\
(-2.094)\end{array}$ & $\begin{array}{l}-0.031 * * \\
(-2.055)\end{array}$ \\
\hline $\operatorname{lnh} c$ & $\begin{array}{l}0.004 \\
(0.039)\end{array}$ & $\begin{array}{c}0.036 \\
(0.352)\end{array}$ & $\begin{array}{c}0.001 \\
(0.014)\end{array}$ & $\begin{array}{c}0.010 \\
(0.095)\end{array}$ \\
\hline $\operatorname{lnTR}$ & & $\begin{array}{l}0.031 * * * \\
(3.335)\end{array}$ & & \\
\hline lnITR & & & $\begin{array}{l}0.011 * \\
(1.918)\end{array}$ & \\
\hline $\operatorname{lnDTR}$ & & & & $0.017 * *$ \\
\hline
\end{tabular}




\begin{tabular}{|c|c|c|c|c|}
\hline & & & & $(2.033)$ \\
\hline \multirow{2}{*}{$\mathrm{W}^{*} \ln \mathrm{Y}$} & $0.061 * *$ & $0.095 * * *$ & $0.056^{* *}$ & $0.093 * * *$ \\
\hline & $(2.436)$ & (2.987) & (2.178) & $(2.903)$ \\
\hline \multirow{2}{*}{$\mathrm{W}^{*} \ln \mathrm{s}$} & $-0.072 * * *$ & $-0.071 * * *$ & $-0.071 * * *$ & $-0.070 * * *$ \\
\hline & $(-3.553)$ & $(-3.514)$ & $(-3.509)$ & $(-3.424)$ \\
\hline \multirow{2}{*}{$\mathrm{W}^{*} \ln (\mathrm{n}+\mathrm{g}+\mathrm{d})$} & -0.038 & -0.040 & $-0.050 *$ & -0.039 \\
\hline & $(-1.511)$ & $(-1.441)$ & $(-1.957)$ & $(-1.351)$ \\
\hline \multirow{2}{*}{$\mathrm{W}^{*} \operatorname{lnh} \mathrm{c}$} & $0.651 * * *$ & $0.59 * * *$ & $0.634 * * *$ & $0.618 * * *$ \\
\hline & (3.995) & (3.600) & (3.916) & (3.744) \\
\hline $\mathrm{W}^{*} \ln \mathrm{TR}$ & & $\begin{array}{l}-0.028 * \\
(-1.746)\end{array}$ & & \\
\hline $\mathrm{W}^{*} \ln I T R$ & & & $\begin{array}{c}0.001 \\
(0.169)\end{array}$ & \\
\hline $\mathrm{W}^{*} \operatorname{lnDTR}$ & & & & $\begin{array}{c}-0.023 \\
(-1.469)\end{array}$ \\
\hline R-squared & 0.9981 & 0.9982 & 0.9981 & 0.9981 \\
\hline Residual variance & 0.001 & 0.0009 & 0.0009 & 0.0009 \\
\hline Sample size & 390 & 390 & 390 & 390 \\
\hline No. of fixed effects & 37 & 39 & 39 & 39 \\
\hline log-likelihood & 815.736 & 822.222 & 818.930 & 818.681 \\
\hline Convergence speed & 0.0796 & 0.1157 & 0.085 & 0.1027 \\
\hline
\end{tabular}

Note: $\mathrm{t}$-values in parentheses; $* * *$ indicates significance at the 0.01 level, $* *$ indicates significance at the 0.05 level, and * indicates significance at the 0.10 level.

\section{Global Spatial Effects}

In a spatial autoregressive model, the regression coefficients alone do not fully explain the influence of explanatory variables on dependent variables, due to the existence of spatial feedback and spillover effects. As proposed by LeSage and Pace (2009), direct, indirect and total effects can be calculated to gauge the impact. Direct effects measure the influence of changing an explanatory variable on the dependent variable, including the feedback effects 
through neighbors and back to the region. Indirect effects can be interpreted as either the influence of changing explanatory variables in a region to the dependent variables of other regions, or the influence to a region from the change in other regions. The numerical values for these two interpretative viewpoints are equal. Total effects are the sum of direct and indirect effects. As the matrix of partial derivatives of the dependent variable with respect to the explanatory variables measures the effects of a change of an explanatory variable in a spatial unit on the dependent variable of all other units, the average of the diagonal elements of this matrix can be used to capture the direct impact, and the average of the row sums of the offdiagonal elements to gauge the indirect impact (LeSage \& Pace, 2009).

As shown in Table 3, tourism revenue as well as its international and domestic components have a significantly positive and direct effect on the economy, accounting for the feedback (regional spillover) effects between provinces. Consistent with the regression coefficients, domestic tourism has a higher direct effect than inbound tourism. However, a negative indirect effect of domestic tourism, although statistically non-significant, offsets the direct effect and results in a non-significant total effect. This implies that the competition between provinces essentially reallocates the domestic tourism revenue, which might improve the regional income inequality. On the other hand, a non-significant yet positive indirect effect of international tourism contributes to a significantly positive total effect. This finding is consistent with Yang and Fik (2014) who argue that inbound tourists tend to visit multiple destinations which generates a positive indirect effect. Due to a higher weight of domestic tourism in the overall tourism revenue, the indirect and total effects of overall tourism are largely driven by the domestic results and display a non-significant value. To reveal the regional distribution of the contribution of tourism in improving the regional income inequality, an investigation of spatial effects of tourism is therefore necessary.

Table 3. Global spatial effects of explanatory variables

\begin{tabular}{|c|c|c|c|c|c|c|c|c|c|}
\hline \multicolumn{4}{|c|}{ Model 2} & \multicolumn{3}{|c|}{ Model 3} & \multicolumn{3}{|c|}{ Model 4} \\
\hline Variable & $\begin{array}{l}\text { Direct } \\
\text { effect }\end{array}$ & $\begin{array}{l}\text { Indirect } \\
\text { effect }\end{array}$ & $\begin{array}{l}\text { Total } \\
\text { effect }\end{array}$ & $\begin{array}{l}\text { Direct } \\
\text { effect }\end{array}$ & $\begin{array}{l}\text { Indirect } \\
\text { effect }\end{array}$ & $\begin{array}{l}\text { Total } \\
\text { effect }\end{array}$ & $\begin{array}{l}\text { Direct } \\
\text { effect }\end{array}$ & $\begin{array}{l}\text { Indirect } \\
\text { effect }\end{array}$ & $\begin{array}{l}\text { Total } \\
\text { effect }\end{array}$ \\
\hline is & $0.052 * *$ & $*-0.072 * * *$ & -0.020 & $0.058 * * *$ & $-0.072 * * *$ & -0.013 & $0.055 * * *$ & $*-0.071 * * *$ & -0.016 \\
\hline $\begin{array}{l}\ln (n+g+ \\
\text { d) }\end{array}$ & -0.025 & -0.048 & $-0.072 * *$ & $-0.032 * *$ & $-0.055 * *$ & $-0.087 * * *$ & $-0.031 * *$ & -0.045 & $-0.076^{* *}$ \\
\hline $\operatorname{lnh} c$ & 0.045 & $0.643 * * *$ & $0.688 * * *$ & 0.005 & $0.661 * * *$ & $0.666 * * *$ & 0.025 & $0.671 * * *$ & $0.695 * * *$ \\
\hline $\operatorname{lnTR}$ & $0.030 * *$ & ${ }^{*}-0.027$ & 0.003 & $0.012 *$ & 0.002 & $0.013^{*}$ & $0.017^{*}$ & -0.022 & -0.005 \\
\hline
\end{tabular}

Notes: $* * *$ indicates significance at the 0.01 level, $* *$ indicates significance at the 0.05 level, and * indicates significance at the 0.10 level.

\section{Results of Local Models}


A local model is specified for each province based on Equation (18). To choose the number of nearest neighbors $m$, the sum of residual variance of 30 local models are calculated for different $m$ and model specifications, following the criterion of selecting the weights matrix $W$. Since the number of border-sharing neighbors ranges from two to seven for each province, the search of $m$ starts from seven. As shown in Figure 5, the lowest values are found when $m$ $=8$. Therefore, eight nearest neighbors are selected for each sub-sample, and the local weight matrix is re-generated for each local model.

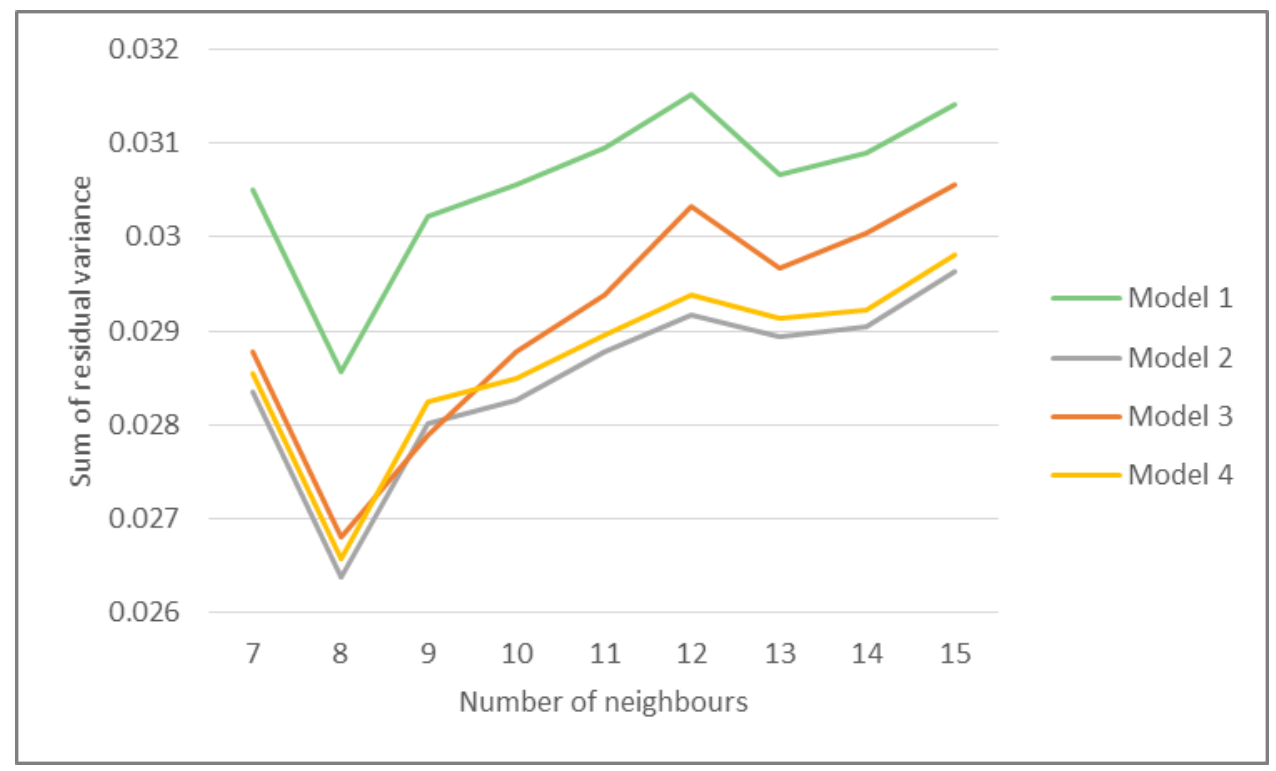

\section{Figure 5. Sum of Residual Variance against the Number of Neighbors}

\section{Local Spatial Effects of Tourism Revenue}

The local estimates provide a clear picture of the distribution of the tourism effects suggested by the global model. The results are mapped on Figure 6 using the R program. As presented by Figure 6(a), tourism development has a significant and positive direct effect on income mainly in the southwest provinces which are the poorest areas in China. This finding verifies the previous conclusion that tourism development does reduce the regional income inequality. As the components of tourism revenue, international tourism and domestic tourism present different patterns. Figures 6(b) and 6(c) demonstrate that inbound tourism primarily contributes to the Northeast and coastal areas, while domestic tourism directly contributes to the Midwest. As the major component, domestic tourism shares a similar spatial pattern of direct effects to the overall tourism revenue. This finding also verifies the prior conclusion that compared with international tourism, domestic tourism contributes more to regional income inequality.

As for the indirect effects, Figure 6(d) illustrates negative values in two provinces (Henan and Sichuan), which implies a significant competition effect with their neighbors. 
Tourists may perceive the nearby areas as substitutes to these two destinations. On the other hand, complementary effects are identified in several clusters where tourists tend to visit jointly. The indirect effects of international tourism are more concentrated while the domestic ones are scattered as shown in Figures 6(e) and 6(f).

Figures 6(g), 6(h) and 6(i) indicate that the total effects of tourism are positive across all regions. The most significant values are observed in the Southwest, which is largely contributed by domestic tourism, and the East, which is backed up by both international and domestic tourism. Among the 11 provinces with significant total effects, six (Guizhou, Yunnan, Gansu, Tibet, Sichuan, and Guangxi) are ranked in the top eight poorest provinces in 2010. Take Yunnan province as an example, a substantially positive contribution of tourism to regional economic growth is identified from the local results. As a less developed region located in the southwest corner of China, Yunnan has rich natural and cultural resources, famous for its tropical rainforests, combined with varied ethnic life-styles and cultures. In fact, Yunnan has experienced a rapid growth in tourism in the last decade. Strong backward and forward linkages between tourism and other industries are prevalent within the local economy especially in the strong attempts to promote provision of souvenirs and other tourist supplies of traditional style in Yunnan (Wen \& Tisdell, 2001).

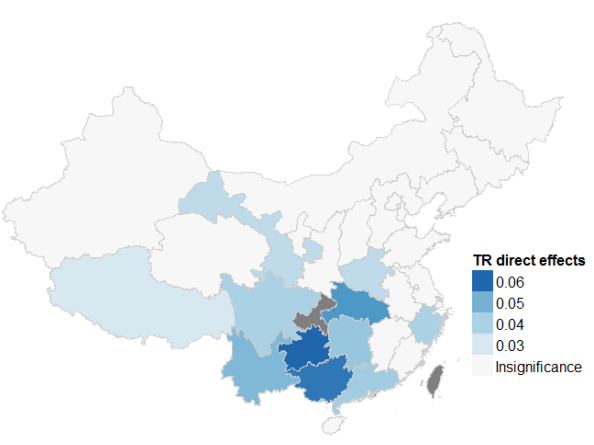

(a)

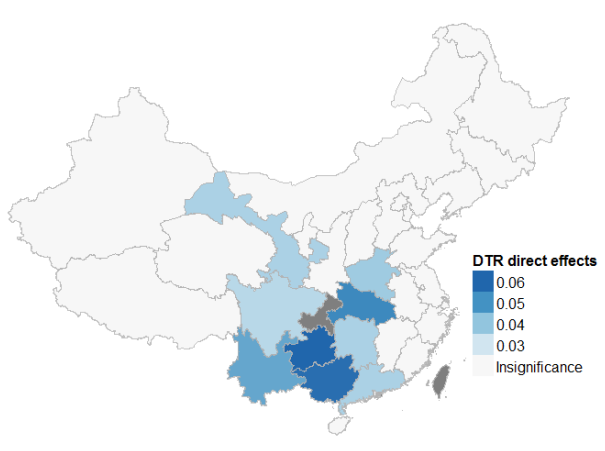

(c)

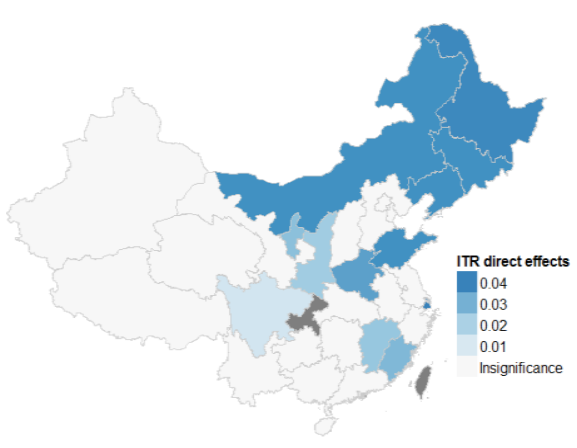

(b)

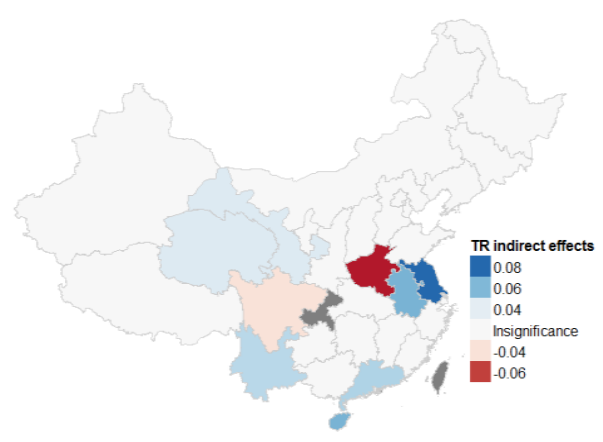

(d) 


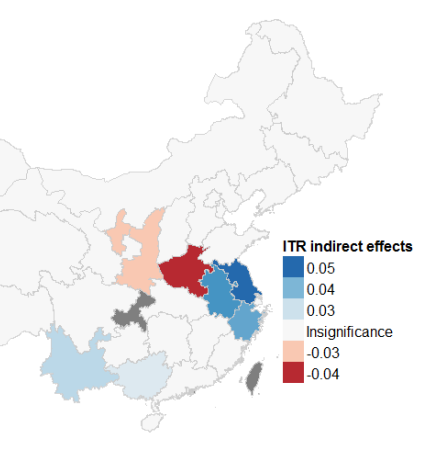

(e)

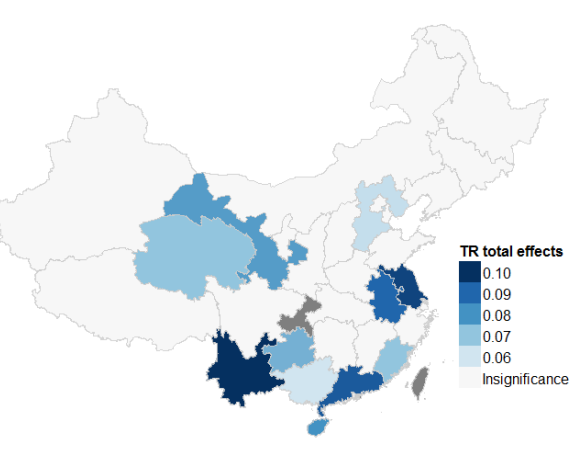

(g)

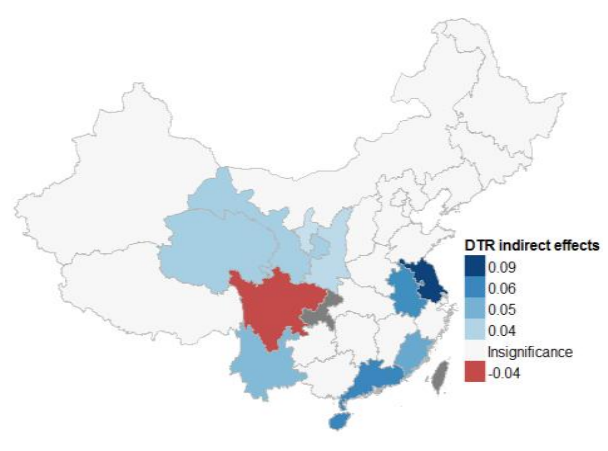

(f)

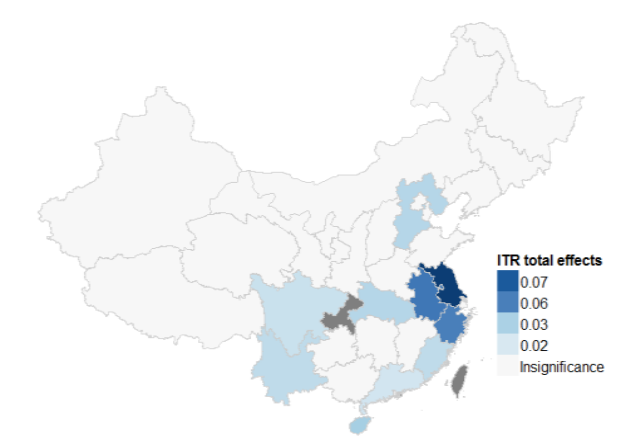

(h)

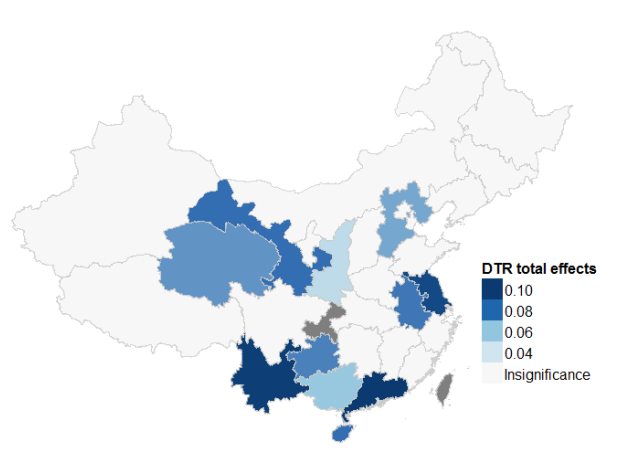

(i)

Figure 6. Local Spatial Effects of Tourism Revenue

\section{CONCLUSION AND POLICY IMPLICATIONS}

This study attempts to supplement the literature by investigating both theoretical and empirical links between tourism development and regional income inequality. From an industrial economics perspective, the theoretical mechanism for how tourism affects regional 
income inequality is identified. Productivity change caused by tourism's vertical (or interindustry) spillovers is recognized as a mediator in the process, whereas the level of economic development is found to be a moderator. By applying the economic conditional convergence model and dynamic panel data estimation techniques, this study empirically tests the effect and importance of tourism on reducing regional inequality in China. It does not only test for the effect of total tourism on regional convergence, but also explores which type of tourism is more efficacious.

Overall, this study supports the claim that tourism can reduce regional income inequality in China. The results are consistent with earlier studies by Proenca and Soukiazis (2008) and Soukiazis and Proenca (2008) in other empirical cases. The results of previous studies on Latin American countries (Eugenio-Martin, Morales, \& Scarpa, 2004), a global panel (Sequeira \& Macas Nunes, 2008) and non-OECD and OECD countries (Lee \& Chang, 2008) have also indirectly supported the above conclusion, demonstrating that tourism contributes more significantly to the economic growth of developing countries or areas than of developed economies.

In China's western regions, even the poorest areas have an abundance of natural, historical and cultural tourism resources that have not been fully utilized or developed due to policy issues, lack of tourism investment, poor infrastructure and other problems. Recently, in order to promote economic growth in western regions and support regional balanced development, the central government has issued a series of preferential policies as part of the 'Western Development Strategy'. Given that tourism sectors can be quickly developed with less investment and lower human capital to reduce the economic gaps with eastern developed areas, it can be expected that tourism development will accelerate the western regions' economic growth with the preferential policy support.

This study also provides evidence that domestic tourism can accelerate regional economic convergence faster than international tourism. Consistent with the aforementioned conclusion, several studies focusing on Australia (Athanasopoulos \& Hyndman, 2008), Peru (O’Hare \& Barrett, 1999), South Africa (Cornelissen, 2005) and China (Bowden, 2005) have suggested that tourism spatial polarization, which is treated as enlarging the existing inequalities, is mainly correlated with international rather than domestic tourism. Developing domestic tourism should facilitate a broader geographical spread of benefits, as domestic tourists are more likely than international tourists to visit regional and remote areas. In China, a wide range of firms and people have benefited from participation in domestic tourism supply due to the comparatively low cost to enter the domestic tourism market, compared with those for the international market (Bowden, 2005). It is domestic, not international, tourism in China that is fueling support for small-scale, labor-intensive forms of tourism that lead directly to poverty alleviation in some areas (Bowden, 2005). Therefore, domestic tourism is more efficacious in promoting regional balanced development. Additional measures should be taken 
by the government to ensure such balance. First, tourism infrastructures and supporting facilities should be developed to meet the domestic tourism boom. For example, more gas stations around highways are needed to satisfy the domestic demand for self-driving travel. Second, legislation on paid holiday leave should be implemented to stimulate domestic tourism demand. Although China began to implement paid leave in 2008, numerous regions and companies still do not practice proper leave policies. Domestic tourism stakeholders can also cooperate closely on its development to generate more potential demand in the near future.

Moreover, this study finds that more provinces are identified as complementary destinations for domestic tourism (e.g., Yunnan, Qinghai, Gansu, Ningxia, and Shaanxi provinces) than for the international tourism (only Yunnan and Guangxi) in China's less developed regions. Some destinations show significant competition effects with their neighbors in less developed regions, specifically Henan and Shaanxi provinces for international tourism, and Sichuan province for domestic tourism. Inappropriate management of these complementary or competition effects may result in unbalanced regional development in China. On this basis, the above destinations should consider collaborative marketing plans and joint promotion campaigns with their neighbors in addition to improving their own competitiveness.

The present study also has some limitations. Its theoretical foundation is based on growth theories, which has some empirical limits, as the assumed infinitesimal divisibility of the production factors is not given in the economic reality. Investments have stepwise effects and the increase is not monotonous. Moreover, the local estimation in this study is based on a trade-off between the sub-sample size and parameter variability in local estimation. Therefore, caution needs to be exercised on local inference. The local estimates must be interpreted with reference to the global model and treated as variation around the global level (Wheeler \& Tiefelsdorf, 2005). Furthermore, this study only focuses on the first-order spatiotemporal models, and higher-order spatiotemporal effects are not taken into account. Future research should consider higher-order spatiotemporal models to allow for a richer dependence structure in space and time. Finally, the present study reveals the spatiotemporal effects but has not explored the path of the spatiotemporal growth process. By simulating shocks and perturbations, further research should investigate the path to reach the long-term equilibrium.

\section{REFERENCES}

Athanasopoulos, G., \& Hyndman, R. J. (2008). Modelling and forecasting Australian domestic tourism. Tourism Management, 29(1), 19-31.

Blomström, M., \& Kokko, A. (1997). How foreign investment affects host countries. In Policy research working paper (Vol. 1745). Washington, DC: World Bank.

Bowden, J. (2005). Pro-poor tourism and the Chinese experience. Asia Pacific Journal of Tourism Research, 10(4), 379-398. 
Chenery, H. B., Robinson, S., \& Syrquin, M. (1986). Industrialization and Growth. New York: Oxford University Press.

Chou, M. C. (2013). Does tourism development promote economic growth in transition countries? A panel data analysis. Economic Modelling, 33(July), 226-232.

Cornelissen, S. (2005). Tourism impact, distribution and development: the spatial structure of tourism in the Western Cape province of South Africa. Development Southern Africa, $22(2), 163-185$.

Cortés-Jiménez, I. (2008). Which type of tourism matters to the regional economic growth? The cases of Spain and Italy. International Journal of Tourism Research, 10(2), 127139.

Cortes-Jimenez, I., Nowak, J. J., \& Sahli, M. (2011). Mass beach tourism and economic growth: lessons from Tunisia. Tourism Economics, 17(3), 531-547.

Deccio, C., \& Baloglu, S. (2002). Nonhost community resident reactions to the 2002 Winter Olympics: The spillover impacts. Journal of Travel Research, 41(1), 46-56.

Deller, S. (2010). Rural poverty, tourism and spatial heterogeneity. Annals of Tourism Research, $37(1), 180-205$.

Elhorst, J. P. (2012). Dynamic spatial panels: Models, methods, and inferences. Journal of Geographical Systems, 14(1), 5-28.

Elhorst, P., Zandberg, E., \& De Haan, J. (2013). The impact of interaction effects among neighbouring countries on financial liberalization and reform: A dynamic spatial panel data approach. Spatial Economic Analysis, 8(3), 293-313.

Ertur, C., Gallo, J. L., \& LeSage, J. P. (2007). Local versus global convergence in Europe: A Bayesian spatial econometric approach. The Review of Regional Studies, 37(1), 82208.

Eugenio-Martín, J. L., Morales, N. M., \& Scarpa, R. (2004). Tourism and economic growth in Latin American countries: A panel data approach. FEEM Working Paper No. 26.

Fan, S., Zhang, X., \& Robinson, S. (2003). Structural change and economic growth in China. Review of Development Economics, 7(3), 360-377.

Gooroochurn, N., \& Hanley, A. (2005). Spillover effects in long-haul visitors between two regions. Regional Studies, 39(6), 727-738.

Göymen, K. (2000). Tourism and governance in Turkey. Annals of Tourism Research, 27(4), 1025-1048.

Haddad, E. A., Porsse, A. A., \& Rabahy, W. (2013). Domestic tourism and regional inequality in Brazil. Tourism Economics, 19(1), 173-186.

Hovhannisyan, N. (2013). Technology sourcing through International business travel. Retrieved November 20, 2014, from Web site: http://www.etsg.org/ETSG2013/Papers/367.pdf

Islam, N. (1995). Growth empirics: a panel data approach. The Quarterly Journal of Economics, 110(4), 1127-1170. 
Islam, N. (2003). What have we learned from the convergence debate? Journal of Economic Surveys, 17, 309-362.

James, R. D., \& Campbell Jr, H. S. (2013). The effects of space and scale on unconditional beta convergence: Test results from the United States, 1970-2004. GeoJournal, 78(5), 803-815.

James, R. D., \& Campbell Jr, H. S. (2014). The impact of space and scale on conditional convergence: test results from the United States (1970-2004). Annals of GIS, 20(1), 1121.

Kadiyali, V., \& Kosová, R. (2013). Inter-industry employment spillovers from tourism inflows. Regional Science and Urban Economics, 43(2), 272-281.

Krakover, S. (2004). Tourism development — centres versus peripheries: The Israeli experience during the 1990s. International Journal of Tourism Research, 6(2), 97-111.

Lazzeretti, L., \& Capone, F. (2009). Spatial spillovers and employment dynamics in local tourist systems in Italy (1991-2001). European Planning Studies, 17(11), 1665-1683.

Lee, C. C., \& Chang, C. P. (2008). Tourism development and economic growth: a closer look at panels. Tourism Management, 29(1), 180-192.

Lee, L., \& Yu, J. (2010). Some recent developments in spatial panel data models. Regional Science and Urban Economics, 40(5), 255-271.

LeSage, J., \& Pace, R. K. (2009). Introduction to spatial econometrics. Boca Raton, FL: CRC Press.

Liargovas, P., Giannias, D., \& Kostandopoulos, C. (2007). An assessment of the community support framework (CSF) funding towards the tourist sector: the case of Greece. Regional and Sectoral Economic Studies, 7(1), 47-66.

Lue, C. C., Crompton, J. L., \& Fesenmaier, D. R. (1993). Conceptualization of multidestination pleasure trips. Annals of Tourism Research, 20(2), 289-301.

Majewska, J. (2015). Inter-regional agglomeration effects in tourism in Poland. Tourism Geographies, 17(3), 408-436.

Mankiw, N. G., Romer, D., \& Weil, D. N. (1992). A contribution to the empirics of economic growth. The Quarterly Journal of Economics, 107(2), 407-437.

Marrocu, E., \& Paci, R. (2011). They arrive with new information. Tourism flows and production efficiency in the European regions. Tourism Management, 32(4), 750-758.

Massidda, C., \& Etzo, I. (2012). The determinants of Italian domestic tourism: a panel data analysis. Tourism Management, 33(3), 603-610.

McMillan, M. S., \& Rodrik, D. (2011). Globalization, structural change and productivity growth. NBER Working Paper No.17143.

Nelson, R. R., \& Pack, H. (1999). The Asian miracle and modern growth theory. The Economic Journal, 109(457), 416-436.

Nicita, A., \& Olarreaga, M. (2007). Information and export performance. Journal of Industry, Competition and Trade, 7(2), 95-111. 
O'Hare, G., \& Barrett, H. (1999). Regional inequalities in the Peruvian tourist industry. Geographical Journal, 165(1), 47-61.

Pace, R. K., \& LeSage, J. P. (2004). Spatial autoregressive local estimation. In J. Mur, H. Zoller, \& A. Getis (Eds.), Recent advances in spatial econometrics (pp. 31-51). New York: Palgrave Publishers.

Páez, A., Farber, S., \& Wheeler, D. (2011). A simulation-based study of geographically weighted regression as a method for investigating spatially varying relationships. Environment and Planning A, 43(12), 2992-3010.

Páez, A., Uchida, T., \& Miyamoto, K. (2002). A general framework for estimation and inference of geographically weighted regression models: 2. Spatial association and model specification tests. Environment and Planning A, 34(5), 883 - 904.

Parrilla, J. C., Font, A. R., \& Nadal, J. R. (2007). Tourism and long-term growth a Spanish perspective. Annals of Tourism Research, 34(3), 709-726.

Peneder, M. (2003). Industrial structure and aggregate growth. Structural Change and Economic Dynamics, 14(4), 427-448.

Perroux, F. (1988). The role of development's new place in a general theory of economic activity. In Higgins, B., \& Savoie, D. J. (Eds.), Regional economic development: essays in honour of François Perroux. Boston: Unwin Hyman.

Proenca, S., \& Soukiazis, E. (2008). Tourism as an economic growth factor: a case study for southern European countries. Tourism Economics, 14(4), 791-806.

Rey, S. J., \& Montouri, B. D. (1999). US regional income convergence: A spatial econometric perspective. Regional studies, 33(2), 143-156.

Sala-i-Martin, X. (1994). Cross-sectional regressions and the empirics of economic growth. European Economic Review, 38(3), 739-747.

Sala-i-Martin, X. X. (1996). The classical approach to convergence analysis. The Economic Journal, 106(437), 1019-1036.

Seckelmann, A. (2002). Domestic tourism - a chance for regional development in Turkey? Tourism Management, 23(1), 85-92.

Sequeira, T. N., \& Macas Nunes, P. M. (2008). Does tourism influence economic growth? A dynamic panel data approach. Applied Economics, 40(18), 2431-2441.

Sinclair, M. T. (1998). Tourism and economic development: A survey. The Journal of Development Studies, 34(5), 1-51.

Solow, R. M. (1956). A contribution to the theory of economic growth. The Quarterly Journal of Economics, 70(1), 65-94.

Song, H., Dwyer, L., Li, G., \& Cao, Z. (2012). Tourism economics research: A review and assessment. Annals of Tourism Research, 39(3), 1653-1682.

Soukiazis, E., \& Proenca, S. (2008). Tourism as an alternative source of regional growth in Portugal: A panel data analysis at NUTS II and III levels. Portuguese Economic Journal, $7(1), 43-61$. 
The $12^{\text {th }}$ Five-year Tourism Development Plan (2011). Retrieved April 10, 2013, from Web site: http://www.bjhhlv.com/newsdetail/4205_1.html

Wanhill, S. (1997). Peripheral area tourism: A European perspective. Progress in Tourism and Hospitality Research, 3(1), 47-70.

Wen, J. J., \& Sinha, C. (2009). The spatial distribution of tourism in China: Trends and impacts. Asia Pacific Journal of Tourism Research, 14(1), 93-104.

Wen, J. J., \& Tisdell, C. A. (2001). Tourism and China's development. Singapore: World Scientific Publishing.

Wen, J., \& Tisdell, C. (1996). Spatial distribution of tourism in China: Economic and other influences. Tourism Economics, 2(3), 235-250.

Wheeler, D., \& Tiefelsdorf, M. (2005). Multicollinearity and correlation among local regression coefficients in geographically weighted regression. Journal of Geographical Systems, 7(2), 161-187.

Williams, A., \& Shaw, G. (No. Ed. 2). (1991). Tourism and Economic Development: Western European Experiences. London: Belhaven Press.

WTTC (World Travel and Tourism Council) (2011). Travel and tourism 2011. Retrieved March 15, 2013, from Web site: http://www.wttc.org/site_media/uploads/downloads/traveltourism2011.pdf

Yang, Y., \& Fik, T. (2014). Spatial effects in regional tourism growth. Annals of Tourism Research, 46, 144-162.

Yang, Y., \& Wong, K. K. (2012). A spatial econometric approach to model spillover effects in tourism flows. Journal of Travel Research, 51(6), 768-778.

Yu, J., \& Lee, L.-F. (2012). Convergence: A spatial dynamic panel data approach. Global Journal of Economics, 1(1), 1-36. 